\title{
Grain Consumption and Production in Virginia: A Trend and Spatial Examination
}

\author{
Peter Caffarelli1", Gustavo Ferreira ${ }^{2 \# *}$, Gordon Groover ${ }^{3}$, Kathryn Boys ${ }^{4}$ \\ ${ }^{1}$ Agricultural Marketing Service, United States Department of Agriculture, Washington DC, USA \\ ${ }^{2}$ Economic Research Service, United States Department of Agriculture, Washington DC, USA \\ ${ }^{3}$ Department of Agricultural and Applied Economics, Virginia Tech, Blacksburg, VA, USA \\ ${ }^{4}$ Department of Agricultural and Resource Economics, North Carolina State University, Raleigh, NC, USA \\ Email: "gustavo.ferreira@ers.usda.gov
}

Received 23 March 2016; accepted 21 April 2016; published 26 April 2016

Copyright (C) 2016 by authors and Scientific Research Publishing Inc.

This work is licensed under the Creative Commons Attribution International License (CC BY).

http://creativecommons.org/licenses/by/4.0/

(c) ()

\section{Abstract}

This article couples an examination of grain production with Virginia's livestock and poultry sector to analyze the overall magnitude and distribution of grain consumption in Virginia. Specifically, this paper describes the sources and trends over time of grain production and consumption; identifies grain surplus (and deficit) areas across Virginia's counties; describes and applies a methodology to quantify livestock and poultry consumption requirements at the state- and county-levels; provides an updated assessment of Virginia's ability to meet its feed grain needs; and discusses implications on the overall distribution system. Important results of the analysis reveal that grain consumption in Virginia is due mainly to demand in the poultry sector (primarily broilers and chickens). Furthermore, grain consumption in this state has generally declined over the last twenty years, due to decreasing livestock population numbers. Coupled with a slight upward trend in grain production, Virginia appears to be increasingly capable of meeting its grain needs. There is, however, an important east-west divide in the state, with western counties requiring more grain than they produce. Since grain does not appear to move from the relatively "production-rich" eastern counties, transportation infrastructure is important to bring in grain from outside the state.

\section{Keywords}

Animal Feed-Grain, County, Grain Consuming Animal Unit

\footnotetext{
\#The views expressed in this article do not necessarily represent those of the Agricultural Marketing Service, Economic Research Service, or the United States Department of Agriculture.

${ }^{*}$ Corresponding author.
} 


\section{Introduction}

Agriculture is Virginia’s most important industry with an estimated yearly economic impact of \$52 billion [1]. The grain, poultry, and livestock sectors are critical contributors to this industry. Though ranked 31 out of 50 in terms of the market value of all agricultural products sold in 2012, Virginia was the fourteenth in the U.S. for poultry and eggs sales [2]. In 2013, cash receipts for Virginia’s major grains (barley, corn, and wheat) and soybeans totaled $\$ 583$ million [3]. These grains and soybeans help support the state’s livestock and poultry sectors, which together generated over $\$ 2.1$ billion in cash receipts in 2013 [3]. ${ }^{1}$

This study analyzes both the overall magnitude and distribution of grain production and consumption in Virginia. More specifically, it describes the sources of grain production and consumption, identifies trends over time, and shows the resulting grain production surplus/deficit areas across Virginia's counties. A county-level examination is important because it leads to new insights and implications, especially concerning transportation. Overall, this study provides an updated assessment of Virginia's ability to meet its grain needs, identifies constraints and opportunities in the current grain production and distribution system, and sheds light on Virginia's grain, livestock, and poultry sectors. Some of the study's main findings are:

- Corn, soybeans, and wheat are the main sources of Virginia grain production;

- Grain production has shown year-to-year variability, due primarily to drought affecting corn production;

- Poultry industry is the largest consumer of grain in the state;

- Generally, the demand for grain by the livestock and poultry sectors exceeds the amount produced in the state, making Virginia a net "importer" of grain from outside the state;

- Virginia’s grain production deficit has been decreasing over time due to declining livestock populations and increasing animal feeding efficiency;

- Most of Virginia's grain is grown in the in the Shenandoah Valley and counties east of Interstate 95;

- Due to an important presence of poultry operations, Virginia's greatest feed requirements are in the Shenandoah Valley area;

- Though the Shenandoah Valley grows a large amount of grain, the region experiences the most severe grain shortages;

- Transportation is crucial to move grain to demand areas to supplement the grain shortages, both within the state and from out of the state; and,

- Grain storage is important because it connects seasonal production with yearlong consumption by poultry and livestock.

Overall, the results provide market insight and foundational knowledge to address the needs of Virginia's grain, livestock, and poultry sectors. In addition, this study helps to uncover and quantify constraints in the grain production market. Finally, the study applies a methodology to estimate the animal feed requirements at the state- and county-levels, which can be replicated for approximation in other states. The remainder of the paper is organized as follows: section 2 reviews relevant literature and previous research, section 3 presents state-level trends of grain consumption and production in Virginia, and section 4 includes the methodology used and the results of the spatial distributions of these two components in Virginia. Concluding remarks, discussion, and policy implications are presented in section 5 .

\section{Literature Review}

A number of studies have examined grain consumption or feed requirements using different estimation methods and geographical scopes (e.g. national or state). Meilke [4], for example, proposed a six-equation simultaneous model (incorporating feed, food and industrial use, exports, previous stocks, and animal units) to calculate and predict levels of feed demand at national level in the United States. More recently, Dikshit and Birthal [5] use animal population numbers and amount fed per animal-type to estimate grain consumption in India. Others studies have used similar procedures as Dikshit and Birthalb [5], but applied the methodology to sub-national regions. For instance, Lammers, Hart, and Honeyman [6] used animal population numbers and corn used per type of livestock to calculate corn consumption in Iowa in 2010. This approach, however, is not wholly representative of grain consumption since corn is just one of the major row crops fed to livestock [7]. Others also invoke the approach of aggregating various types of rations fed to livestock. Huffman and Kenyon [8] developed estimates of consumption for Virginia using animal population quantities and the amount fed per animal-type to

\footnotetext{
${ }^{1}$ The commodities included in the calculation are broilers, cattle/calves, milk, turkeys, and eggs.
} 
calculate corn and soybean consumption from 1965 to 1997. While that study is limited by a narrower portfolio of feed grains considered, it offers additional insight by taking the analysis beyond the state to the agricultural district level. ${ }^{2}$ In another study, Tiffany and Fruin [9] examined grain (corn, oats, soybean meal) consumption and distribution patterns at the county-level in Minnesota in 1999 using similar procedures to Huffman and Kenyon.

Differing in method from the aforementioned studies, the Economic Research Service (ERS) of the United States Department of Agriculture (USDA) has been estimating variables related to grain consumption at the national level for over a hundred years [10]. The approach used by this organization employs the following steps: 1) obtain population numbers for livestock (by type) fed during the year being considered; 2) estimate the number of "animal units" by weighting the animals according to their relative feed consumption (e.g. one broiler does not consume the same amount as one dairy cow); and 3) multiply the number of animal units by the tons of grain consumed per animal unit to estimate the total annual grain consumption [11] [12]. At least two studies have used this approach to investigate grain consumption at the state-level, one by Conley, Nagesh, and Salame, and another by the Agricultural Marketing Service (AMS) of the USDA. The AMS study computed the average number of animal consuming units from 2006 to 2010 for all states [13], while Conley, Nagesh, and Salame [14] calculated corn consumption by grain consuming animal units as well as the total corn utilization (including other avenues for grain such as industrial use and seed) for each state over the 2004-2010 period.

The present study applies and expands upon the approach used by the ERS to develop county-level spatial insights. Extending this analysis to the county-level requires identification of sufficient proxy variables since state-level variables are not always available at the county-level, and an approach to increase the spatial accuracy of mapped data. Combining the ERS' methodology with these additional steps leads to new insights and provides a methodology that may be applied in other regions.

\section{Trends in Virginia Grain Consumption and Production}

\subsection{Data Sources and Methodology}

Analysis encompassed in this paper focuses on the major components of the feed grain supply chain in Virginia: grain production and consumption by livestock and poultry from 1992 to 2014. ${ }^{3}$ The research primarily makes use of publically available data from USDA's National Agricultural Statistics Service (NASS). ${ }^{4}$ This study applies the previously described ERS approach to calculate the demand for grain by Virginia's livestock sector.

Grain production (or supply) is derived by aggregating barley, corn, soybeans, and wheat production for each year within the period of study. Demand for feed grains by the population of eleven animal groups (including various types of cattle and poultry, hogs, sheep, and horses) are used in the calculation of grain consumption. Following the ERS methodology, livestock and poultry population numbers were converted (where applicable) to a September-August year to match the main crop production and marketing [11] [12]..$^{5}$

Virginia's grain production consists of four main crops: barley, corn, soybeans, and wheat. ${ }^{6}$ Crop production data at the state-level were obtained from the Crop Production, Annual Summary reports, released by NASS. In order to compare grain production against grain consumption, production is converted from bushels to tons using the conversion factors shown in Table 1 . The conversion is done by multiplying the bushels produced in a given year for each grain by their respective weights. An additional step must be taken to convert soybeans to soybean meal-the portion relevant to animal feeds. ${ }^{7}$ The production (in tons) of barley, corn, soybean meal, and wheat is then aggregated to arrive at "total grain production" for each year. ${ }^{8}$

\footnotetext{
${ }^{2}$ USDA's National Agricultural Statistics Service divides a state into several "agricultural districts," so it provides more in-depth information in terms of location. Virginia comprises seven agricultural districts.

${ }^{3}$ The terms "grain supply”/“grain production” and "grain demand”/“grain consumption” are used interchangeably.

${ }^{4}$ Data are available via NASS' online “Quick Stats” [15] and official reports posted on their website. The names of the relevant NASS reports for each commodity are provided in the Appendix.

${ }^{5}$ The crop marketing year in the U.S. for corn and soybeans is September to August, and June to May for barley and wheat. The ERS converts data to September-August.

${ }^{6}$ Although technically an oilseed, in this analysis, soybeans are included in the "grains" category because of its importance and similar role in the grain supply chain.

${ }^{7}$ Specifically, a 60 -pound bushel of soybeans generates 47.3 pounds of soybean meal [8].

${ }^{8}$ Total production is used because grain consumption cannot be separated into individual components (i.e., "the amount of 'corn' consumed").
} 
Table 1. Factors to convert grain provided in bushels to tons.

\begin{tabular}{ccc}
\hline Crop & Pounds/Bushel & Conversion Factor (Tons/Bushel) \\
\hline Barley & 48 & 0.0240 \\
Corn & 56 & 0.0280 \\
Wheat and soybeans & 60 & 0.0300 \\
Soybean meal & 47.3 & 0.0237 \\
\hline
\end{tabular}

Next, to calculate grain consumption, the initial steps involve identifying the relevant livestock groups and collecting their population numbers from 1992 to 2014 [11] [12]. With its wide agricultural portfolio, Virginia livestock include cattle (dairy, beef on feed, other beef), poultry (broilers, turkeys, layers, and pullets), hogs, sheep, and horses. Table 2 describes the eleven considered livestock commodities and their respective variable type (e.g, "inventory," "production,” etc.). While not specified in the ERS (or AMS) approach, horses are added to the types of livestock included since they are an important component of Virginia agriculture [16]. Details regarding the consumption calculations such as where the data may be found in the NASS reports, which variables were converted to a September-August marketing year, and any additional steps taken are provided in the Appendix.

After animal population numbers are gathered or estimated, the next steps consist of estimating the number of "animal units" and generating an aggregate estimate of total animal units for each year. The concept of "animal units" addresses the need for comparable units-different animals have different environmental impacts and feed requirements [17]. Thus, ERS developed the "grain consuming animal unit” (GCAU) to weigh the livestock groups appropriately. ERS weights were estimated by comparing the grain consumption of different livestock species to the dry-weight grain consumption of one dairy cow. Table 3 presents the GCAU factors for the considered types of livestock [11] [18]. The factors imply that the annual grain feed requirements of one dairy cow are equivalent to approximately 524 broilers, 68 turkeys, or 4.6 hogs. ${ }^{9}$ To estimate the number of GCAUs for each animal type, the population for a given species is multiplied by its respective GCAUfactor. ${ }^{10}$ The total (annual) grain consuming animal units in Virginia are then calculated by summing GCAU estimates for all livestock types (e.g. cattle GCAUs, poultry GCAUs, etc.) within a given year.

The last step in estimating grain consumption is to multiply the total yearly GCAUs by the amount of grain consumed per animal unit in the appropriate year (Figure 1). Equation (1) shows the different pieces of information that are used to estimate grain consumption. Data on feed per animal unit is obtained from ERS on a marketing year basis. ${ }^{11}$ The numbers represent all feeds, including the major energy feeds (corn, wheat, etc.) and oilseed meals. Figure 1 shows that the amount of grain fed per grain consuming animal unit has varied from about 2.1 tons to 2.7 tons [19]. Importantly, these numbers correspond roughly to the grain rations fed to livestock and poultry. ${ }^{12}$ According to the ERS, the amount of feed per grain consuming animal unit reflects changes in feeding efficiency and grain prices over time $[11]{ }^{13}$ Rising feed prices can alter short-term trends of feed per GCAU as higher feed prices push livestock producers to slaughter at lower weights and put more animals (such as cattle) on pasture [11]. Conversely, when feed prices decline, feed use per GCAU increases as more animals are fed for a longer period and moved to feedlots [11]. Generally, the amount of grain consumed per animal unit has declined over the period, but increased the past two years.

\footnotetext{
${ }^{9}$ For example, the broiler factor is 0.0020 and the dairy cow factor is $1.0475 .1 .0475 / 0.0020=524$.

${ }^{10}$ For example, to generate GCAUs, the number of dairy heifers is multiplied by 0.1761 , the number of broilers by 0.0020 , the number of hogs by 0.2285 , and so on for the remaining livestock commodities.

${ }^{11}$ “2012/13" is an example of a marketing year, which corresponds to 2012 in this analysis.

${ }^{12}$ The unit conversion of 2.1 to 2.7 tons of feed is between 4,200 and 5,400 pounds. According to Jacob and Pescatore [20], 10 to 11 50-pound bags of feed are needed to produce fifty 5-pound commercial-type broilers (more bags are required to produce heavier chickens). One GCAU of broilers is 500 chickens. Therefore, about 10550 -pound bags are needed for 500 chickens, or 5,250 pounds of feed (6,750 pounds are needed to produce 500 6-pound chickens). Layers require about four 50-pound bags of feed per month to feed 25 hens [20], which is about 4,423 pounds of feed for one GCAU of layers ( 4 bags for 25 hens * 50 pounds per bag * 12 months * 46.08 layers per GCAU / 25 hens). As an approximation of the grain consumption by a dairy cow (which is about one GCAU), the normal lactation period is between 290 and 310 days, with an average of 296 days [21]. According to Huffman and Kenyon [8], a lactating cow is fed 17 pounds of grain concentrates daily, which is about 5,032 pounds during the period. Fisher and Hutjens [22] estimate that the diet for a dairy cow could include 25 pounds of grain mix per day (in addition to substantially higher wet feed such as forage).

${ }^{13}$ For example, grain faced a severe price shock in 1995 and 1996, which caused a decrease in the amount fed to livestock [23]. In addition, Karlin [24] finds a good fit between the amount fed per grain consuming animal unit and the price (at least for corn).
} 
Table 2. Livestock and poultry considered in assessment of Virginia grain consumption.

\begin{tabular}{ccc}
\hline Livestock/Poultry Type & Data Description & Estimated 2014 “Population” \\
\hline Cattle, dairy cows & Inventory on January 1 & 93,000 \\
Cattle, dairy heifers & Inventory on January 1 & 43,000 \\
Cattle, beef, cattle on feed & Inventory on January 1 & 20,000 \\
Cattle, beef, other & Inventory, derived & $1,314,000$ \\
Poultry, broilers & (see the Appendix) & $258,900,000$ \\
Poultry, turkeys & Production (head) during year & $16,000,000$ \\
Poultry, layers & Production (number raised) during year & $2,949,167$ \\
Poultry, pullets & Inventory, average, derived (see the Appendix) & $9,998,286$ \\
Hogs & Derived (see the Appendix) & 70,000 \\
Sheep & Pig crop & 75,000 \\
Horses and mules & Inventory on January 1 & 215,000 \\
\hline
\end{tabular}

Table 3. Grain consuming animal unit factors for different animals [13].

\begin{tabular}{cc}
\hline Livestock/Poultry Type & GCAU Factor \\
\hline Cattle, Dairy Cows & 1.0475 \\
Cattle, Dairy Heifers & 0.1761 \\
Cattle, Beef, Cattle on Feed & 1.5323 \\
Cattle, Beef, Other & 0.0547 \\
Poultry, Broilers & 0.0020 \\
Poultry, Turkeys & 0.0155 \\
Poultry, Layers & 0.0217 \\
Poultry, Pullets & 0.0054 \\
Hogs & 0.2285 \\
Sheep & 0.0194 \\
Horses and Mules & 0.2043 \\
\hline
\end{tabular}

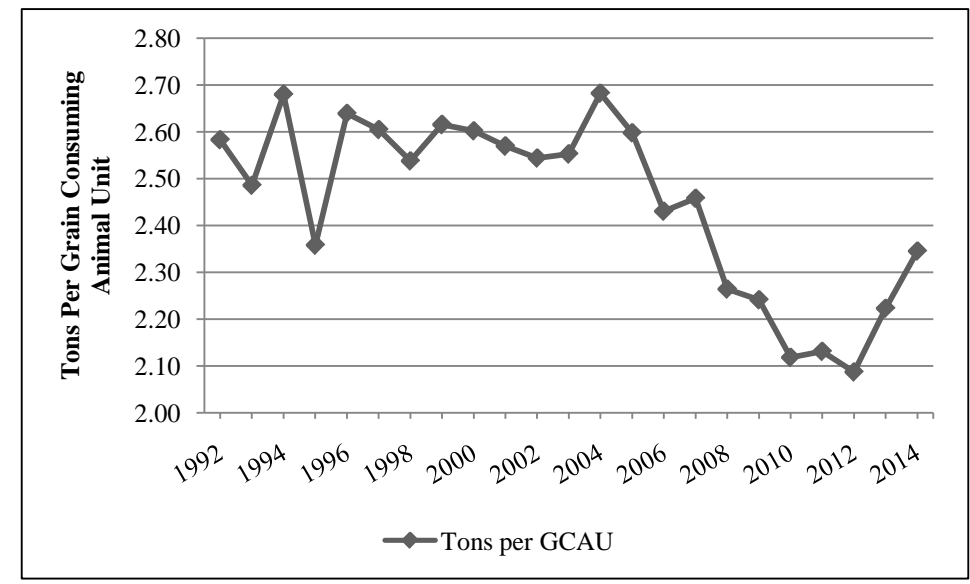

Figure 1. Tons of feed consumed per grain consuming animal unit (nationally), 1992-2014 [19].

$$
\text { GrainConsumption }_{t}=a_{t} \sum_{i}^{11} b_{i t} c_{i}
$$

Where $i=$ the animal group (dairy cattle, dairy heifers, ..., horses)

$a=$ tons of grain consumed per animal unit in time $t$ (Figure 1)

$b=$ the animal group's population in time $t$

$c=$ the animal group's GCAU factor (Table 3)

$t=$ the year $(1992,1993, \ldots, 2014)$ 


\subsection{State-Level Results}

The state of Virginia was ranked 29th in the U.S. for sales of grains and oilseeds in 2012 [2]. Grain production in the state is mainly characterized by corn, soybean (converted to soybean meal for this analysis), and wheat production, with relatively smaller amounts of barley production (Figure 2). The respective shares of total grain production in 2014 were 55 percent for corn, 23 percent for soybean meal, 20 percent for wheat, and 2 percent for barley. Annual fluctuations in total grain production are mainly due to low productivity (yields) of Virginia's corn crop [25]. Nevertheless, grain production in Virginia has experienced a slight positive increase over the period from 1992 to 2014. In fact, grain production in 2013 and 2014 reached amounts comparable to the peak levels in the 1980s. ${ }^{14}$ For a more detailed examination of Virginia's grain production, see Caffarelli, Ferreira, Groover, and Boys [25].

Poultry accounts for the largest share of Virginia livestock production with 287.8 million units (number of head) out of a total of 289.7 million animals in $2014 .{ }^{15}$ However, the conversion of livestock populations into comparable units based on feed consumption changes the relative weight of different animal populations. For instance, grain consuming animal units appropriately increase the weight of cattle while lessening that of poultry. This is important because the grain consuming animal units show the overall trends in grain consumption that are due to changes in the different animal populations. ${ }^{16}$ According to Prater and O’Neil [13], Virginia was ranked 22nd in the United States in the average number of grain consuming animal units from 2006 to $2010 .{ }^{17}$ Overall, however, the number of grain consuming animal units has generally declined over the period of 1992 to 2014, as shown in Figure 3. This downward trend is mainly due to generally declining populations of broilers, turkeys, layers, hogs, and dairy cows. ${ }^{18}$ The reduction in the number of hogs raised in Virginia is particularly notable from 2010 to $2014 .^{19}$

As previously explained, estimates of total grain consumption by livestock are obtained by multiplying the number of GCAUs by the amount of grain consumed per unit. Due to the combined effects of declining livestock populations (reflected in Figure 3) and generally increasing feeding efficiency (Figure 1), the total amount of grain consumed in Virginia has decreased (Figure 4). From 2009 to 2014, the average share of total grain consumption was 73 percent for poultry, 18 percent for cattle, 6 percent for hogs, and 4 percent for other livestock. In recent years, poultry's share of total consumption has increased while the share of hogs has decreased. ${ }^{20}$

In a past study of grain consumption in Virginia, Huffman and Kenyon [8] examined corn and soybean consumption from 1965 to 1997. Their approach made use of animal population numbers and the specific rations of corn and soybeans fed to each animal commodity. For the comparable years of 1992 to 1997, Huffman and Kenyon identified increasing corn and soybean consumption. Though their results are not directly analogous, a comparison is useful. Huffman and Kenyon's findings are mostly in accordance with the observations found in this analysis, with the exception of 1995-a marketing year that the ERS saw a significant drop in the amount consumed per GCAU. ${ }^{21}$ Interestingly, current estimates showing decreasing demand for grain contradict Huffman and Kenyon's prediction that growth in corn and soybean consumption in Virginia would continue.

Figure 5 presents the aggregate grain production and consumption by livestock and poultry for Virginia from 1992 to 2014. The decline in grain consumption has been accompanied by generally increasing grain production levels, especially in more recent years. Consequently, Virginia’s grain deficit has been diminishing over time and even turned into a surplus in 2013. From 2009 to 2014, Virginia's livestock and poultry sectors demanded an average of 2.61 million tons of grain, while grain production averaged 2.19 million tons. When combined,

\footnotetext{
${ }^{14}$ For example, peak grain production levels prior to 2012 were in 1982, 1981, and 1984 with 101, 97, and 96 million bushels (respectively), including barley, corn, soybeans, and wheat. Grain production in Virginia was 100 and 96 million bushels in 2013 and 2014, respectively.

${ }^{15}$ The calculation for "poultry" includes broilers, turkeys, layers, and pullets.

${ }^{16}$ For example, to say that Virginia's livestock "declined by 10,000 head” is meaningless in terms of a discussion on grain consumption as animals of different species do not consume the same amount of grain. Instead, it is useful to convert all animals to the same unit and discuss changes in that comparable unit.

${ }^{17}$ The five leading states in terms of GCAUs over this period were Texas, Iowa, North Carolina, Nebraska, and Kansas.

${ }^{18}$ In terms of the other livestock and poultry populations, pullets and beef cattle on feed have generally declined, and, while sheep numbers have declined earlier in the period, some of the population has returned.

${ }^{19}$ Interestingly, a fall in Virginia’s hog production in 2014 was not due to the porcine epidemic diarrhea virus (PEDv), which devastated hog production in other states [26].

${ }^{20} \mathrm{Graphs}$ that depict trends in the shares of total grain consumption in Virginia by different livestock groups over time as well as breakouts of the shares within the poultry and cattle groups are available from the authors upon request.

${ }^{21}$ Grain faced a severe price shock in 1995 and 1996, which caused a decrease in the amount fed to livestock [23].
} 


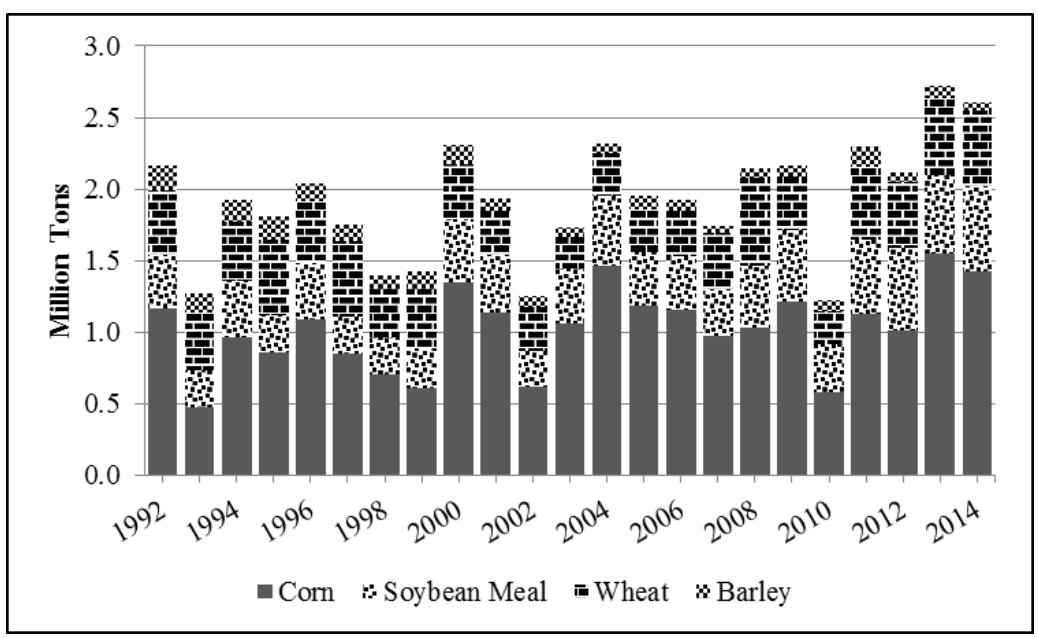

Figure 2. Grain production in Virginia, 1992-2014 (million tons) [15].

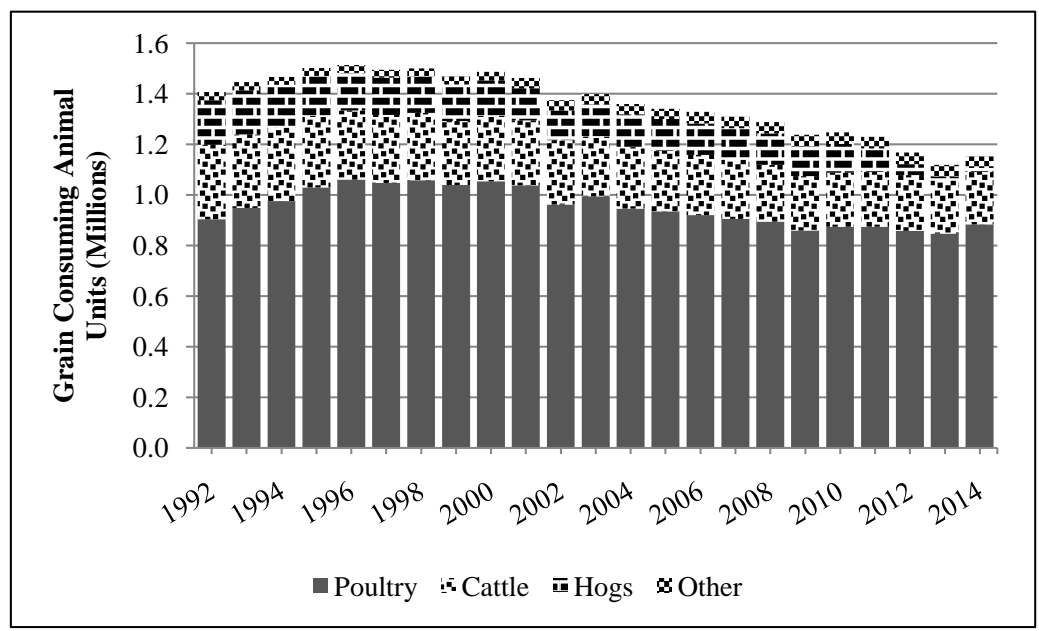

Figure 3. Number of grain consuming animal units in Virginia, 1992-2014 (authors' calculations).

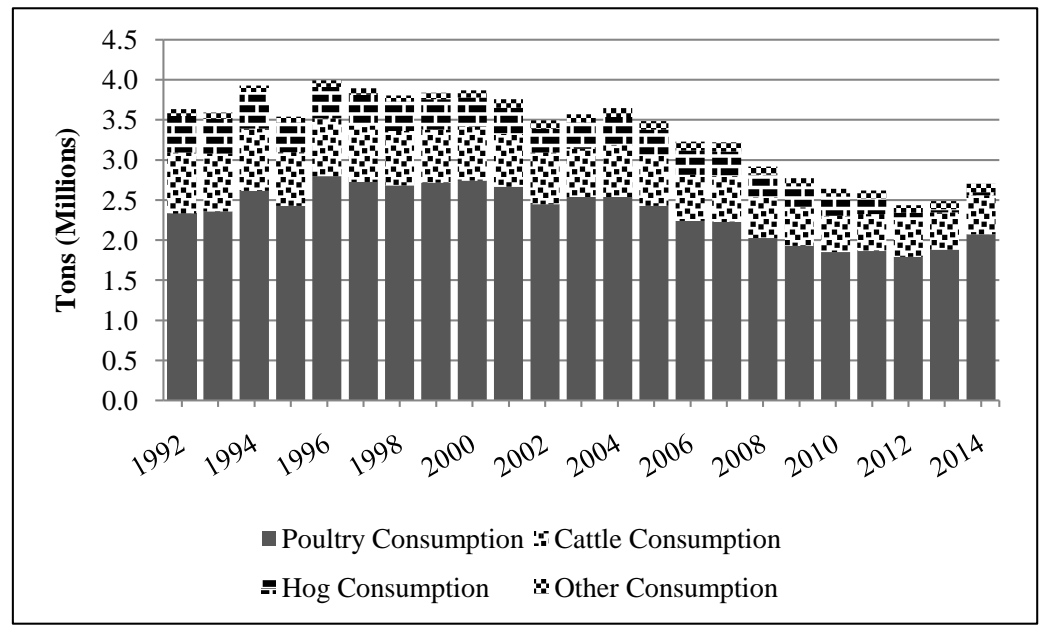

Figure 4. Estimated grain consumption in virginia by livestock and poultry, 1992-2014 (authors' calculations). 


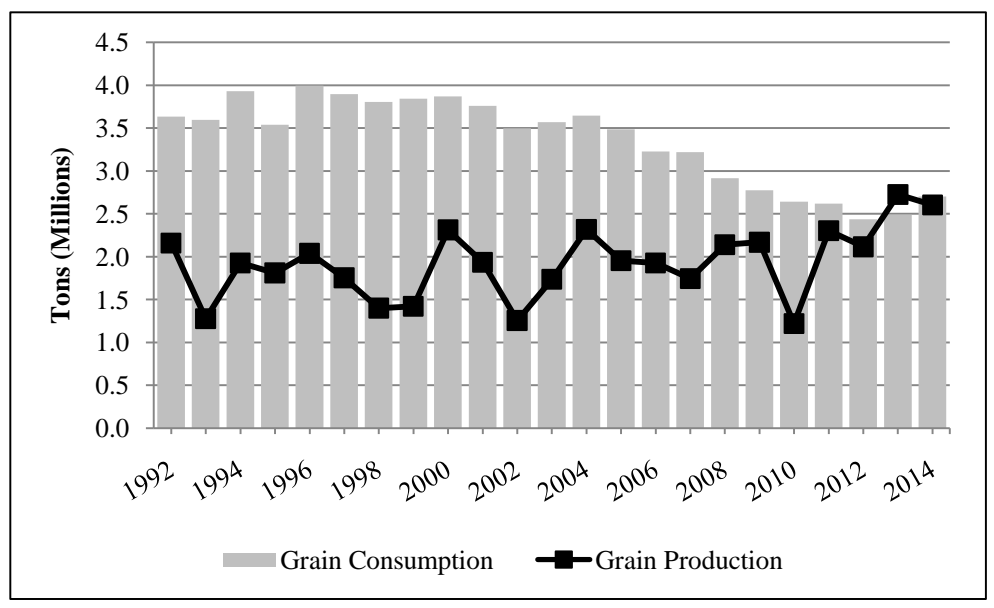

Figure 5. Grain consumption (by livestock and poultry) and production in Virginia, 1992-2014 (authors' calculations).

these estimates indicate that Virginia experienced an average annual grain production shortage of 422 thousand tons (or 15.1 million bushels ${ }^{22}$ ). Comparing the average production deficit in 2003-2008 to 2009-2014, the shortage in Virginia fell by 952 thousand tons or 69 percent.

It is important to note that these estimates understate Virginia's grain production deficit. There are, of course, additional uses grain such as that which is exported, used for seed, industrial uses, or for human consumption [27]. While it is more difficult to estimate the amount of Virginia-grown grain that goes to human consumption, ${ }^{23}$ estimates of Virginia's grain exports are available from the ERS from 2000 to 2014 [28]. From 2009 to 2014, Virginia exported an average of 16 percent of corn (149 thousand tons), 65 percent of soybean (418 thousand tons), and 63 percent of wheat (223 thousand tons) production, for a combined 790 thousand tons. Grain exports fluctuated from 2000 to 2010 (average 652 thousand tons annually), but have increased every year since 2010.

Combining this export information with the previous estimates of livestock and poultry production demand suggests that Virginia required 1.21 million additional tons of grain annually from 2009 to 2014. These shortages are met primarily through importing in a substantial amount of grain by railroad from the U.S. Midwest region, including the states of Ohio, Illinois, Indiana, and others [13] [29]. Between2006 and 2010, Virginia imported an annual average of 2.48 million tons of grain that originated in the Midwest [29]. ${ }^{24}$

The impact of the seasonality of grain production is another important issue that merits more detailed discussion. Grain consumption is similar year-round, but in Virginia, barley and wheat are harvested in June and early July, and corn and soybeans are harvested in the fall [30]. As a result of this timing disparity, grain storage and transportation are important to keep a supply of grain available outside harvest times and to move grain when and where it is needed. Virginia's grain stocks held by commercial facilities are highest in December following the corn and soybean harvest [31]. ${ }^{25}$

\section{Spatial Distribution of Virginia Grain Consumption and Production}

\subsection{Data Sources and Methodology}

To gain additional spatial insights into Virginia’s grain markets, county-level production and use estimates can

\footnotetext{
${ }^{22}$ Assuming 56 pounds/bushel.

${ }^{23}$ For instance, most of Virginia's wheat fields are soft red winter wheat, which is used to make cakes, pastries, and crackers. Other wheats for bread and pasta (for human consumption) must be imported into Virginia from other states.

${ }^{24}$ During that time (2006 to 2010), Virginia’s grain production deficit averaged 1.12 million tons, and exports averaged 655 thousand tons, for a combined 1.77 million tons. Note: the analysis does not include product that is used for industry/human or quantities that move across state lines by truck.

${ }^{25}$ For more information on how grain production compares to grain storage in Virginia, see [25]. Interestingly, fall grain stocks and production compared against storage capacity (examining potential storage shortfalls at harvest) show that Virginia's storage is not as limited as other states [32].
} 
also be generated. In this analysis, county-level estimates are just generated for 2012 to correspond to the most recent Census available, the 2012 Census of Agriculture [33]. The Census is conducted every five years by NASS and provides a detailed picture of agriculture in the U.S. Among other variables, data are collected on production expenses, the market value of products, and operator characteristics.

The methods used to estimate grain consumption and production at the county-level are largely analogous to parallel those used in the state-level calculations. There are, however, two unique issues to be considered: 1) the degree to which Census data resemble the "expected" production or livestock population numbers developed in the previous annual calculations, and 2) the "accuracy" of the production and population distributions displayed on a map of Virginia's counties. The first issue arises because NASS does not collect all of the same variables in the periodic Census that it gathers annually (which are used in the state-level calculations). For example, the ERS methodology uses "broiler production" and the "pig crop" as a proxy for broiler and hog feed consumption, respectively. However, NASS does not collect data on the pig crop or broiler production in the Census so adjustments are required. The second issue is due to the fact that NASS does not publish data for every county as a means to avoid disclosing information on individual operations. ${ }^{26}$

In order to simplify the language, the first issue is termed "magnitude accuracy" to what extent the aggregated county-level estimates are equal to the state-level estimate for a particular variable. The second issue is referred to as "distribution accuracy"-how exact the spread is across Virginia's counties. The issue of magnitude accuracy is mitigated, first, by the fact that most of the variables in the Census are the same (or reasonably similar) to those used in the annual state-level calculations and, second, because county-level data from the Census estimate 98 percent of the expected 2012 grain consumption. In the absence of a similar match, variables are selected that most closely reflect the expected 2012 state-level population for the given animal-type. The second issue of distribution accuracy is not a substantial problem since most of the county data are disclosed (often 90 percent or more) for the production and livestock consumption categories. As a general procedure, the non-disclosed data are distributed equally across non-disclosed counties. However, wherever possible, additional measures are taken and explained to enhance the distributional accuracy of certain livestock groups (see the Appendix).

As in the annual calculations, grain production at the county-level consists of barley, corn, soybeans (meal), and wheat. Since the variables used to estimate the grain supply at the state-and county-levels both represent "production" for the year, the issue of "magnitude accuracy" issue is not present (Table 4). ${ }^{27}$ In addition, the

Table 4. Comparison of state-and county-level Virginia grain production.

\begin{tabular}{|c|c|c|c|c|}
\hline & Barley & Corn & Soybeans $^{\mathrm{a}}$ & Wheat \\
\hline \multicolumn{5}{|l|}{ State-Level Variable: } \\
\hline Type $^{\text {b }}$ & $\begin{array}{l}\text { Production } \\
\text { (bushels) }\end{array}$ & $\begin{array}{c}\text { Production } \\
\text { (bushels) }\end{array}$ & $\begin{array}{l}\text { Production } \\
\text { (bushels) }\end{array}$ & $\begin{array}{c}\text { Production } \\
\text { (bushels) }\end{array}$ \\
\hline Time Frame/Date & 2012 & 2012 & 2012 & 2012 \\
\hline Amount & $2,870,000$ & $36,050,000$ & $24,360,000$ & $15,360,000$ \\
\hline \multicolumn{5}{|l|}{ County-Level Variable: } \\
\hline Type $^{\text {b }}$ & $\begin{array}{l}\text { Production } \\
\text { (bushels) }\end{array}$ & $\begin{array}{c}\text { Production } \\
\text { (bushels) }\end{array}$ & $\begin{array}{l}\text { Production } \\
\text { (bushels) }\end{array}$ & $\begin{array}{c}\text { Production } \\
\text { (bushels) }\end{array}$ \\
\hline Time Frame/Date & 2012 & 2012 & 2012 & 2012 \\
\hline Amount & $2,905,047$ & $33,984,647$ & $22,680,879$ & $14,804,947$ \\
\hline Percentage Difference & $1.2 \%$ & $-5.7 \%$ & $-6.9 \%$ & $-3.6 \%$ \\
\hline Amount Disclosed & $2,607,902$ & $33,703,317$ & $22,552,678$ & $14,578,900$ \\
\hline Amount Non-Disclosed & 297,145 & 281,330 & 128,201 & 226,047 \\
\hline Percent Disclosed & $89.8 \%$ & $99.2 \%$ & $99.4 \%$ & $98.5 \%$ \\
\hline Percent Non-Disclosed & $10.2 \%$ & $0.8 \%$ & $0.6 \%$ & $1.5 \%$ \\
\hline
\end{tabular}

a. Reflects soybeans rather than soybean meal. b. In the case of grain production, the variable "types” are the same at the state-and county-levels are the same. (This is not true for all livestock and poultry.)

\footnotetext{
${ }^{26}$ For example, NASS does not release the information if a county contains less than three operations.

${ }^{27}$ In fact, due to the comprehensiveness and effort involved in conducting the Census, the county-level data are likely a more accurate representation of the "true" production numbers in Virginia. Even so, the annual production values are not replaced by Census numbers in order to maintain a consistent variable to observe year-to-year changes.
} 
issue of "distribution accuracy" is small since 95 percent of the grain production at the county-level is disclosed. Thus, it is reasonable to believe that the quantities reflected on the maps (in the Results section) are the expected amount and in the appropriate location.

To obtain tons of grain produced in each county, final steps include converting bushels to tons (by multiplying the amount of each crop by its respective factor in Table 1) and aggregating the tons of barley, corn, soybean meal, and wheat.

Akin to the annual grain consumption calculations, the first step is identifying the variables to represent the various livestock groups. However, as mentioned previously, an important consideration to bear in mind is that the same variables used in the annual estimates are not collected in the Census. For comparison purposes, Table 5 lists the variables used in the state-and county-level estimates for each animal group. Some variables such as those used to represent horses, cattle, and sheep are the same (or essentially the same) in both calculations, while "most representative" proxies are used for others like poultry and hogs. A comparison of the selected Census variables to the annual ones, and a description of issues related to magnitude or distribution accuracy and steps taken to address these issues is provided in the Appendix. The remaining steps required to estimate county-level GACUs are the same as those used previously to generate state-level estimates.

\subsection{County-Level Results}

A series of county-level maps of Virginia are provided that show the location and levels of grain production, consumption, and their resulting difference. Categories displayed in all maps applied the Jenks' optimization method, a procedure automatically calculated in the software program which minimizes the variance within groups and maximizes the variance between groups [34].

Virginia's grain production encompasses almost every county and three independent cities: Chesapeake, Suffolk, and Virginia Beach. The state produced an estimated 2.1 million tons of grain in 2012, from 70 thousand tons of barley, 952 thousand tons of corn, 680 thousand tons of soybeans, and 444 thousand tons of wheat [33]. For purposes of comparing production against consumption, soybeans are converted to soybean meal. ${ }^{28}$ As shown in Figure 6, most of the grain in Virginia is grown and harvested in the Shenandoah Valley and eastern counties. ${ }^{29}$ Large amounts of all four crops are produced in the Eastern Shore (Northampton and Accomack counties). These two counties produced a combined 200 thousand tons or 10 percent of the state's total grain supply in 2012.

Similar to grain production, feed is required throughout the state. Figure 7 displays the total grain consumption by livestock and poultry in each of Virginia's counties (in tons). Most of Virginia's poultry operations are located in the Shenandoah Valley; given the poultry sector comprises a substantial portion of the state's total

Table 5. Variables for the state-level and county-level grain consumption estimates.

\begin{tabular}{ccc}
\hline Animal Group & State-Level (Annual) Variable & County-Level (Census) Variable \\
Cattle, Dairy Cows & Inventory on Jan. 1, 2013 & Inventory on Dec. 31, 2012 \\
Cattle, Dairy Heifers & Inventory on Jan. 1, 2013 & Not available \\
Cattle, Beef, Cattle on Feed & Inventory on Jan. 1, 2013 & Inventory on Dec. 31, 2012 \\
Cattle, Beef, Other & Derived (see the Appendix) & Derived \\
Poultry, Broilers & Production (head) in 2012 & Sold/moved in 2012 \\
Poultry, Turkeys & Production (head) in 2012 & Inventory on Dec. 31, 2012 \\
Poultry, Layers & Inventory (average) in 2012 & Inventory on Dec. 31, 2012 \\
Poultry, Pullets & Derived (see the Appendix) & Inventory on Dec. 31, 2012 \\
Hogs & Pig crop in 2012 & Inventory on Dec. 31, 2012 \\
Sheep & Inventory on Jan. 1, 2013 & Inventory on Nov. 1, 2006 \\
Horses and Mules & Inventory on Nov. 1, 2006 &
\end{tabular}

\footnotetext{
${ }^{28}$ As a linear transformation, the relative distribution remains the same.

${ }^{29}$ Maps of country-level crop production for barley, corn, soybean meal, and wheat, and utilization by most livestock types are available from the authors upon request.
} 


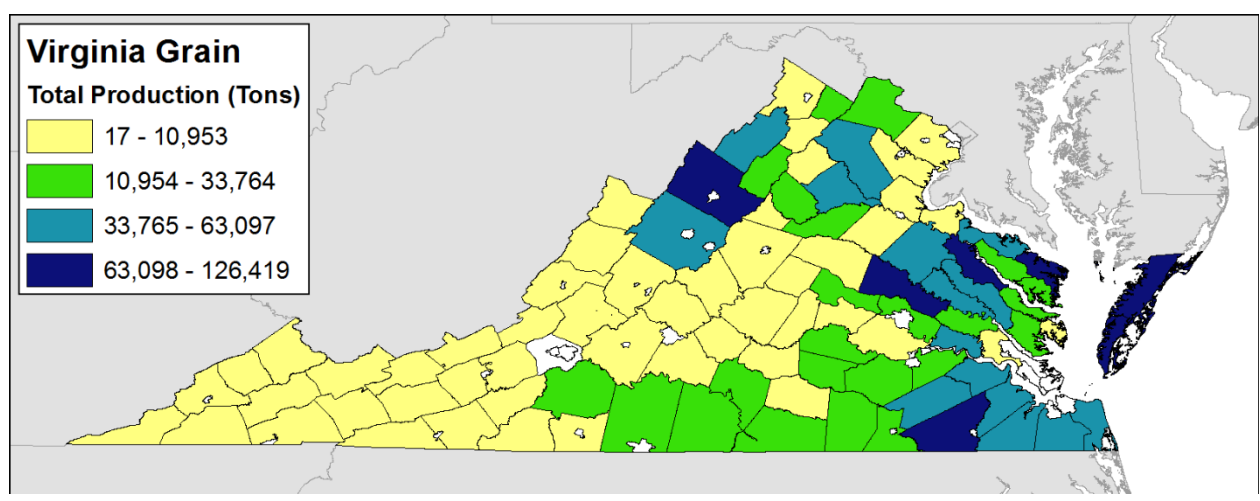

Figure 6. Map of total grain production in Virginia by county, 2012.

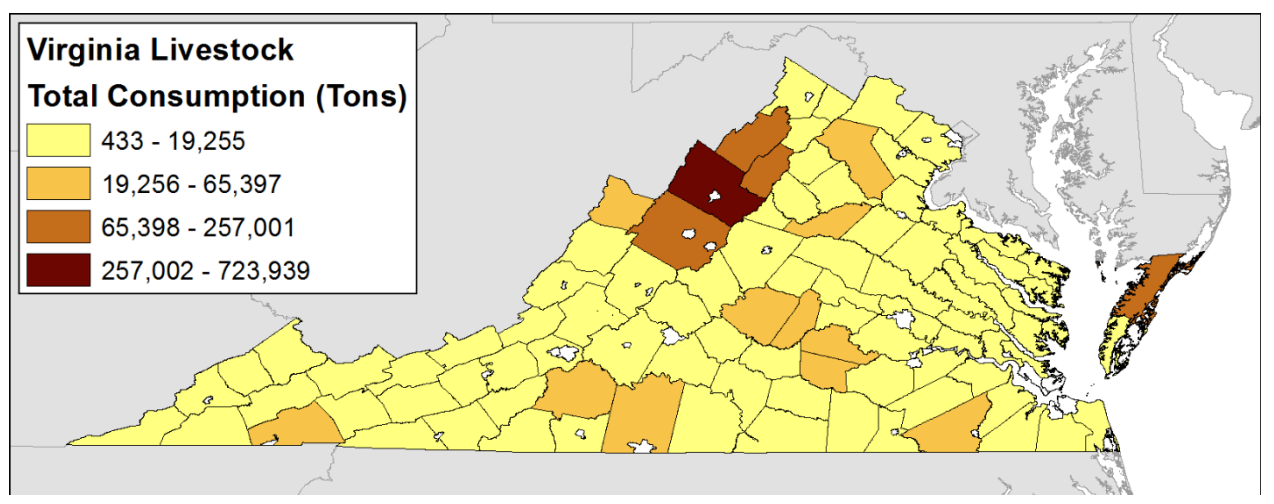

Figure 7. Map of total grain consumption (by livestock and poultry) in Virginia by county, 2012.

demand of the feed grains this region is an important area of grain consumption. The top-five counties requiring the most grain in 2012 include Rockingham (724 thousand tons), Augusta (257 thousand tons), Page (243 thousand tons), and Shenandoah (147 thousand tons) of the Shenandoah Valley region and Accomack (152 thousand tons) of the Eastern Shore (which also houses significant broiler populations). With over 1.5 million tons of the state's total grain consumption of 2.4 million tons, these five counties accounted for 64 percent of Virginia's grain needs (up slightly from 63 percent in 2007).

To gain additional insight into grain surplus and deficit areas in Virginia, grain consumption is subtracted from grain production. Results reveal that the state is primarily divided east-west, with western counties experiencing grain shortages and eastern counties having excess grain (Figure 8). These results are due to the aforementioned fact that eastern Virginia grows large quantities of grain, especially relative to its livestock needs. A notable exception is Accomack County on the Eastern Shore, which, despite producing the most grain in Virginia with 126 thousand tons in 2012, still requires additional grain imports. Home to a substantial amount of Virginia's poultry operations, the counties in the Shenandoah Valley have the state's greatest grain shortages. The four counties of Rockingham, Page, Augusta, and Shenandoah have grain shortages of 639 thousand tons, 228 thousand tons, 195 thousand tons, and 109 thousand tons, respectively. With a combined grain deficit of 1.2 million tons, these four counties account for 74 percent of Virginia's total grain shortage in 2012 (up from 70 percent in 2007). An additional nine other counties had a grain shortfall of at least ten thousand tons in 2012.

At the more aggregated agricultural district level, Huffman and Kenyon [8] reached similar conclusions: the northern agricultural district (which includes Rockingham and Shenandoah counties) experiences the greatest grain shortages while the eastern agricultural district generates the highest grain surpluses. ${ }^{30}$ It is important to recognize that this country-level snapshot of grain supply and utilization is limited by the omission of flows of grain from one county to another, and it does not include grain destined for export markets, industry, or human use. Consequently, county-level deficits may be under-or over-estimated. Nevertheless, this analysis identifies

\footnotetext{
${ }^{30}$ The deficit in the northern agricultural district estimated by Huffman and Kenyon [8] may even be understated because Augusta County, the county with the second highest grain shortage, is included in the "western" agricultural district.
} 


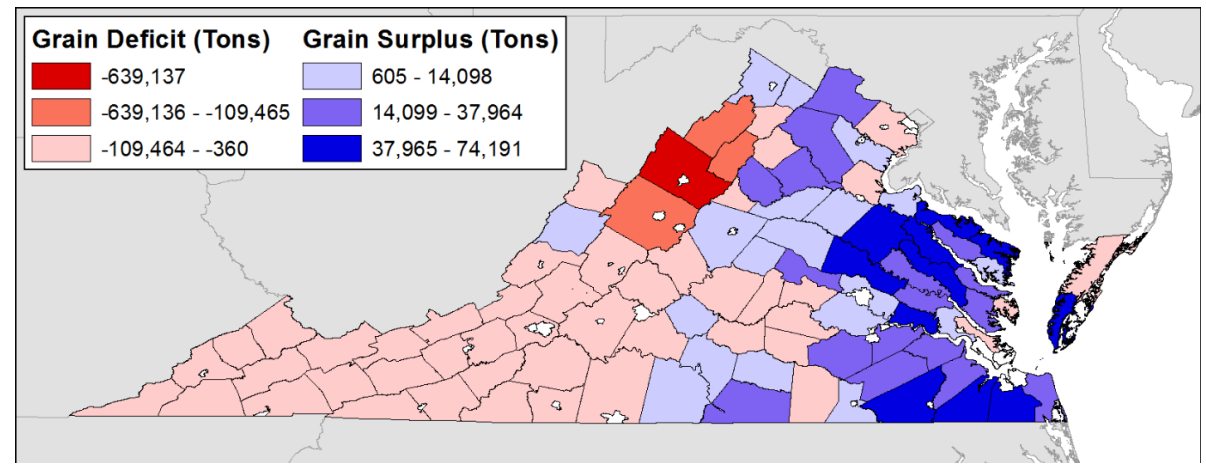

Figure 8. Map of Virginia’s grain deficits and surpluses (production less consumption by livestock and poultry) by county, 2012.

the areas that are likely to be comparatively more constrained or well-supplied with grain for livestock and poultry production.

\section{Discussion and Conclusions}

Virginia is a state which produces a rich diversity of crops and agricultural products. Virginia's agricultural producers raise poultry, cattle, hogs, sheep, and horses and, combined with their value-added products, generated over \$2.1 billion in cash receipts in 2013 [3]. In terms of grains, Virginia’s important crops include barley, corn, soybeans, and wheat. This grain serves as an important input in livestock production.

The requirements of Virginia's livestock sector have generally exceeded the state's grain production; this problem is compounded when grain exports and grain for human consumption and industry uses are considered. Overall then, Virginia is a grain deficit state. Across the period of study from 1992 to 2014, feed consumption in Virginia is generally declining. This is due to 1) decreasing livestock populations (primarily declining broilers, turkeys, hogs, and dairy cattle) and 2) increased feed efficiency by U.S. livestock producers [11]. The finding of declining livestock and poultry populations in Virginia is particularly noteworthy because USDA's Office of the Chief Economist predicts increasing U.S. poultry and pork production through 2025 [35]. These trends, combined with a slight positive trend in grain production, have led to a decrease of Virginia's net grain deficit.

Virginia's narrowing grain deficit has several potentially important implications. Likely due, in part, to reduced competition for grain from livestock producers, Virginia's grain exports have increased every year since 2010. Further, increased grain production, and consumer demand trends in favor of locally produced foods, may encourage increased local sourcing, which would help retain dollars in the Virginia economy as opposed to being transferred to grain exporting states [8]. Notable increases in local feed-grain sourcing, however, would require that producers consider the impact and risk associated with reliance on variable levels of local grain supplies.

At a local level, Virginia's grain shortages and surpluses show an east-west divide, with western counties generally requiring more grain than they grow. Due to substantial poultry operations (the largest share of total consumption), most of the state's grain consumption is in the Shenandoah Valley. Grain production is significant in that region as well as in the state's eastern counties. An examination of grain consumption and production together reveals that grain shortfalls are the most notable in the Shenandoah Valley.

The analysis yields several other important implications, especially with respect to transportation. Broadly, as a grain deficit state, transportation is critical since grain must come into the state to meet the residual needs of the livestock sector in excess of grain production. Much of Virginia's grain shortfall is supplemented by interstate grain supplies shipped by railroad [29]. More specifically, transportation is crucial to areas such as the Shenandoah Valley (and other western counties) that rely on moving the grain they grow to storage to ensure that the grain is ultimately available where and when it is needed. This is especially pertinent because grain surpluses in eastern Virginia do not move back west. Despite their geographic proximity, grain buyers in the Shenandoah Valley generally find it more economical to import grain by rail from the Midwest rather than grain hauled by truck from the east [8]. ${ }^{31}$ Transportation must be efficient and timely to move grain from farm, to sto-

\footnotetext{
${ }^{31}$ Excess grain beyond the state’s livestock requirements in the east could enter Virginia's ports for export and supply feeding operations in North Carolina.
} 
rage, to demand areas. In the event of limited transportation or increasing transportation costs, a series of questions would need to be addressed concerning: the financing, location, and type (s) (e.g. rail, truck, etc.) of future transportation infrastructure. Private enterprises, state and local governments, producer associations, industry boards, cooperatives, and farmers should be actively involved and have a role in these decisions.

Furthermore, the findings of this study present the opportunity for geographically targeted agricultural policy. For instance, Virginia's counties in the Shenandoah Valley are identified as the area facing the most severe grain shortages. Importantly, the magnitude of the grain shortfall leaves livestock and poultry producers in this area subject to market events not always in their control. For one, a deficit of 1.2 million tons is equivalent to about 46 thousand large semi-trucks [36], which implies some of the shortage can only be reasonably supplied by rail. This leaves some grain buyers largely captive to railroad service, prices, and infrastructure capacity and constraints. Further, while all areas are affected by local supply availability, counties in the Shenandoah Valley are particularly tied to outside supplies, including their availability and price. If outside supplies were to become unavailable or more costly, the livestock and poultry producers in this region would be particularly impacted [37]. Finally, livestock and poultry producers in the Valley are dependent on grain storage to ensure grain is available when needed. These operations rely on the capacity, quality, and location of on- and off-farm grain storage for much of the year. Thus, the amount, location, availability, and condition of grain supplies, transportation, and storage are important to profitability of the industry.

This study suggests several areas for potential future research. First, investigation is needed to explore the reasons why Virginia's livestock and poultry populations have declined to make a more complete assessment of the industry. Next, further research examining grain transportation, the flows of grain in, out, and within Virginia, and the economic factors behind those flows would increase the understanding of issues related to grain production and consumption and offer important insights policymakers. Finally, information regarding the production, consumption, and transportation of feed grains must be integrated with data on Virginia's grain storage to more fully understand the nature of, and opportunities and constraints, affecting the state's grain supply chain. Combined, this information would offer insights into both the current performance and expansion potential of Virginia's valuable grain and livestock sectors.

\section{References}

[1] Rephann, T.J. (2013) The Economic Impacts of Agriculture and Forest Industries in Virginia. University of Virginia, Weldon Cooper Center for Public Service. http://www.coopercenter.org/sites/default/files/publications/Virginia\%20AgricultureForest\%202012reva_0.pdf

[2] Virginia NASS Field Office (2014) State Agriculture Profile for Virginia. Virginia Field Office. http://www.nass.usda.gov/Quick_Stats/Ag_Overview/stateOverview.php?state=VIRGINIA

[3] Virginia Department of Agriculture and Consumer Services (VDACS) (2015) Virginia’s Top 20 Farm Commodities.

[4] Meilke, K.D. (1975) An Aggregate U.S. Feed Grain Model. Agricultural Economics Research, 27, 9-18. http://ageconsearch.umn.edu/bitstream/147237/2/3Meilke_27_1.pdf

[5] Dikshit, A.K. and Birthal, P.S. (2010) India’s Livestock Feed Demand: Estimates and Projections. Agricultural Economics Research Review, 23, 15-28. http://ageconsearch.umn.edu/bitstream/92091/2/2-AK-Dikshit.pdf

[6] Lammers, P.J., Hart, C.E. and Honeyman, M.S. (2012) Estimating Corn Use by Iowa Livestock and Poultry. Ag Decision Maker, Iowa State University Extension and Outreach. https://www.extension.iastate.edu/agdm/livestock/pdf/b2-55.pdf

[7] Capehart, T. (2015) Feed Grains Database, Documentation. United States Department of Agriculture, Economic Research Service (USDA-ERS). http://www.ers.usda.gov/data-products/feed-grains-database/documentation.aspx

[8] Huffman, B.A. and Kenyon, D.E. (1999) Corn and Soybean Consumption and Production in Virginia. Virginia Tech, Department of Agricultural and Applied Economics. http://ageconsearch.umn.edu/bitstream/14840/1/rr990041.pdf

[9] Tiffany, D.G. and Fruin, J. (2002) Filling the Livestock Feed Troughs of Minnesota and Beyond. University of Minnesota, Department of Applied Economics. http://ageconsearch.umn.edu/bitstream/13851/1/p02-10.pdf

[10] United States Department of Agriculture, Economic Research Service (USDA-ERS) (1963) Livestock Feed Relationships 1909-1963. USDA-ERS. http://ageconsearch.umn.edu/bitstream/153759/2/sb337.pdf

[11] Capehart, T. (2013) Animal Unit Calculations-First Projections for the 2013/14 Crop Year. United States Department of Agriculture, Economic Research Service (USDA-ERS). http://www.ers.usda.gov/media/1225074/fds13esa.pdf

[12] Capehart, T., Allen, E. and Bond, J. (2013) Feed Outlook. Publication. United States Department of Agriculture, Eco- 
nomic Research Service (USDA-ERS).

http://usda.mannlib.cornell.edu/usda/ers/FDS//2010s/2013/FDS-01-15-2013.pdf

[13] Prater, M.E. and O’Neil Jr., D. (2013) State Grain Rail Statistical Summary. United States Department of Agriculture, Agricultural Marketing Service (USDA-AMS). http://dx.doi.org/10.9752/TS066.06-2013

[14] Conley, D.M., Nagesh, R.G.A. and Salame, E.J. (2012) Supply and Utilization of Corn in the United States, by State, 2004-2010. University of Nebraska-Lincoln. http://extensionpublications.unl.edu/assets/pdf/rb351.pdf

[15] United States Department of Agriculture, National Agricultural Statistics Service (USDA-NASS). Quick Stats. http://quickstats.nass.usda.gov/

[16] Rephann, T.J. (2011) The Economic Impact of the Horse Industry in Virginia. University of Virginia, Weldon Cooper Center for Public Service. http://www.coopercenter.org/sites/default/files/publications/horse study final.pdf

[17] Minnesota Department of Agriculture (MDA). Animal Unit Calculation Worksheet. http://www.mda.state.mn.us/animals/feedlots/feedlot-dmt/animalunitcalcwksht.aspx

[18] Hollis, P. (2002) Southeast Grain Production Changing. Southeast Farm Press. http://southeastfarmpress.com/southeast-grain-production-changing

[19] United States Department of Agriculture, Economic Research Service (USDA-ERS) (2015) Quantities Fed and Feed per Grain-Consuming Animal Unit. Data. USDA-ERS. http://www.ers.usda.gov/data-products/feed-grains-database/feed-grains-yearbook-tables.aspx

[20] Jacob, J. and Pescatore, T. (2012) How Much Will My Chickens Eat? University of Kentucky Cooperative Extension Service. http://www2.ca.uky.edu/agc/pubs/ASC/ASC191/ASC191.pdf

[21] Adams, R.S., Hutchinson, L.J. and Ishler, V.A. Troubleshooting Problems with Low Milk Production. Penn State Extension, Dairy.

http://extension.psu.edu/animals/dairy/nutrition/nutrition-and-feeding/troubleshooting-guides/troubleshooting-problem s-with-low-milk-production

[22] Fischer, D. and Hutjens, M. (2007) How Many Pounds of Feed Does a Cow Eat in a Day? eXtension. http://articles.extension.org/pages/37808/how-many-pounds-of-feed-does-a-cow-eat-in-a-day

[23] Light, J. and Shevlin, T. (1998) The 1996 Grain Price Shock: How Did It Affect Inflation? US Bureau of Labor Statistics. http://www.bls.gov/mlr/1998/08/art1full.pdf

[24] Karlin, J. (2014) Corn Feed Demand. DTN/The Progressive Farmer. http://www.dtnprogressivefarmer.com/dtnag/common/link.do?symbolicName=/ag/blogs/template1\&blogHandle=agfu ndamental\&blogEntryId=8a82c0bc464a513801496149f54d1d08

[25] Caffarelli, P., Ferreira, G., Groover, G. and Boys, K. (2014) Grain and Soybean Production and Storage in Virginia: A Summary and Spatial Examination. Virginia Cooperative Extension. https://pubs.ext.vt.edu/AAEC/AAEC-60/AAEC-60-pdf.pdf

[26] Murphy, R. (2014) Virginia Pork Producers Enjoy High Profits While Battling Epidemic. Daily Press. http://www.dailypress.com/news/isle-of-wight-county/dp-nws-isle-wight-pig-disease-impacts-20141021-story.html

[27] Lazarus, S.S., Hill, L.D. and Thompson, S.R. (1980) Grain Production and Consumption for Feed in the North Central and Southern States with Projections for 1985, 1990, and 2000. University of Illinois at Urbana-Champaign. https://www.ideals.illinois.edu/bitstream/handle/2142/8614/grainproductionc00laza.pdf?sequence=1

[28] United States Department of Agriculture, Economic Research Service (USDA-ERS) Data (2015) State Export Data. USDA-ERS. http://www.ers.usda.gov/data-products/state-export-data.aspx

[29] Caffarelli, P., Ferreira, G., Groover, G. and Boys, K. (2013) Virginia’s Grain “Imports” by Rail: A Summary. AAEC Extension Update (Virginia Tech). http://news.cals.vt.edu/fbm-update/2013/08/07/virginias-grain-imports-by-rail-a-summary/

[30] United States Department of Agriculture, National Agricultural Statistics Service (USDA-NASS) (2010) Field Crops: Usual Planting and Harvesting Dates. USDA-NASS. http://usda.mannlib.cornell.edu/usda/current/planting/planting-10-29-2010.pdf

[31] Caffarelli, P., Ferreira, G., Groover, G. and Boys, K. (2014) Off-Farm Grain Stocks and Capacity in Virginia. AAEC Extension Update (Virginia Tech). http://news.cals.vt.edu/fbm-update/2014/02/05/off-farm-grain-stocks-and-capacity-in-virginia/

[32] Caffarelli, P. and Gastelle, J. (2015) Grain Storage Capacity Affects Transportation Timing and Patterns. USDA-AMS Grain Transportation Report. http://dx.doi.org/10.9752/TS056.10-15-2015

[33] United States Department of Agriculture, National Agricultural Statistics Service (USDA-NASS) (2014) 2012 Census of Agriculture for Virginia. USDA-NASS. http://www.agcensus.usda.gov/Publications/2012/Full_Report/Volume_1,_Chapter_1_State_Level/Virginia/vav1.pdf 
[34] Esri. GIS Dictionary, Jenks’ Optimization. Esri Support. http://support.esri.com/en/knowledgebase/GISDictionary/term/Jenks'\%20optimization

[35] United States Department of Agriculture, Office of the Chief Economist (USDA-OCE) (2015) USDA Agricultural Projections to 2024. USDA-OCE. http://www.ers.usda.gov/media/1776036/oce151.pdf

[36] Iowa Department of Transportation (2014) Barge Comparison. Iowa DOT. http://www.iowadot.gov/compare.pdf

[37] Piggott, N.E., Shumaker, G.A. and Curtis Jr., C.E. (2005) A Guide to Price-Risk Management in Grain Marketing for North Carolina, South Carolina, and Georgia. North Carolina Cooperative Extension. http://www4.ncsu.edu/unity/lockers/users/n/nick/basis_piggott_shumaker_curtis.pdf

[38] Penn State Extension. Modern Meat Chicken Industry. Penn State Extension, Poultry Educational Resources. http://extension.psu.edu/animals/poultry/topics/general-educational-material/the-chicken/modern-meat-chicken-industr $\mathrm{y}$

[39] Virginia NASS Field Office. Annual Statistical Bulletin for Virginia. Data. Virginia Field Office. http://www.nass.usda.gov/Statistics_by_State/Virginia/Publications/Annual_Statistical_Bulletin/index.php

[40] Virginia NASS Field Office (2008) 2006 Virginia Equine Report. Virginia Field Office. http://www.nass.usda.gov/Statistics_by_State/Virginia/Publications/Equine/equine2007full.pdf 


\section{Appendix: Additional State- and County-Level Methodologies}

The appendix describes the state-and county-level procedures in more detail.

\section{Additional State-Level Methodology}

Cattle data were obtained from NASS' Cattle, Final Estimates and January Cattle publications, which provide annual January 1 inventories for four major cattle types: dairy cows, dairy heifers, beef cattle on feed, and other beef cattle. These cattle inventory numbers are used by the ERS as a proxy for the number fed during the year. In Cattle, ${ }^{32}$ dairy cow inventory for Virginia includes "Milk cows that have calved" (of the "Cattle Inventory by Class" table). Dairy heifer inventory is represented by "Milk cow replacement” from the "Heifers 500 pounds and over" grouping. On the other hand, beef cattle on feed inventory are retrieved from the "Total Number of Cattle on Feed” table. Finally, other beef cattle numbers are calculated by subtracting the previous three cattle categories from the "All cattle and calves" category. Since these inventory variables reflect a single point in time, they do not need to be converted to a September-August marketing year. Inventory on January 1, 2013, for example, corresponds to the 2012-year in the analysis.

Estimates of grain consumption by poultry are based on four major groups: broilers, turkeys, layers, and pullets. NASS' Poultry-Production and Value (an annual summary) and Poultry-Production and Value, Final Estimates publications are the data sources for broilers and turkeys and represent the number of animals fed during the year. Since the broiler population comes from the number produced from December 1 to November 30, a conversion is needed to adjust to a September-August marketing year. This is achieved by combining 25 percent of the prior year's production and 75 percent of the current year's production [12]. The turkey population, however, represents the number of head raised from September 1 to August 31, and no data transformation is needed.

NASS’ Chicken and Eggs, Annual Summary and Chicken and Eggs, Final Estimates publications contain data on the average number of layers on hand in Virginia every month ("Average Number of All Layers on Hand During the Month—States and United States” table). Following ERS procedures [12], the layer population fed during the year is calculated by averaging the September through August months (e.g. September 2010 to August 2011 for the 2011 marketing year). ${ }^{33}$

Data for pullets come from NASS' monthly Chicken and Eggs. The ERS calculation for pullets is one-half the egg-type chick hatch plus the pullets placed in the broiler supply flocks for the September-August marketing year [12]. The egg-type chick hatch comes from the "Egg-Type Chicks Hatched by Month-United States” table and the pullets placed in the broiler supply flocks comes from the "Intended Placements of Broiler-Type Pullet Chicks for Hatchery Supply Flocks by Month and Total” table. Since this only calculates yearly totals of pullets for the entire United States, the AMS takes an additional step to calculate shares of pullets at the state-level. For instance, to calculate the number of pullets in Virginia, total U.S. pullets are multiplied by Virginia's percentage share of the combined U.S. broiler and layer populations [13].

Information on hog population is found in NASS' December issue of Quarterly Hogs and Pigs and Hogs and Pigs, Final Estimates. The ERS estimates the number of hogs fed annually through a variable titled the pig crop, which is found in the “Annual Sows Farrowing, Pigs per Litter, and Pig Crop-States and United States” section. Since the data are collected quarterly, the ERS combines quarters to create two groups: the "spring pig crop" (December to May) and the "fall pig crop" (June to November). The computation for pigs requiring feed is 20 percent of the prior year's spring pig crop, 100 percent of the prior year's fall pig crop, and 80 percent of the current year's spring pig crop [12]. For example, for the 2011 marketing year, the total number of hogs fed is equal to 20 percent of the 2010 spring pig crop, 100 percent of the 2010 fall pig crop, and 80 percent of the 2011 spring pig crop. For Virginia, the pig crop is only disclosed for the entire year (December to November) so it is assumed that half of the yearly pig crop is "spring" and the other half is "fall.,"34

\footnotetext{
32 The Final Estimates contain similar names for column and tables in which to locate data. This is the case for other animals as well.

${ }^{33}$ Due to data availability limitations, the calculation for years 1992 to 1994 is somewhat different. Prior to 1994, NASS collected average monthly layer data on 20 states; of which, Virginia was not included. For 1992 and 1993, the variable "average number of layers" (in the "Layers and Egg Production: Annual Average Number of Layers" table of the 1989-93 Final Estimates) was used. Layers were then calculated by repeating the ERS procedure for broilers: taking 25 percent of the previous year with 75 percent of the current year. 1994 is a combination of the two with 25 percent of the 1993 average layer inventory and 75 percent of the 1994 December to August months.

${ }^{34}$ Prior to 1993, NASS collected data on Virginia's pig crop every quarter. These additional data points were used to make the estimate for 1992 more accurate.
} 
NASS presents sheep data in its Sheep and Goats and Sheep and Goats, Final Estimates reports. Similar to cattle, the ERS uses the January 1 inventory to approximate the sheep population that was fed during the year [8]. Data come from the "All Sheep and Lambs" column of the Sheep and Goats publication ("Sheep and Lamb Inventory by Class-States and United States” table). As with cattle, inventory on January 1, 2013, for example, corresponds to 2012 in the analysis. It is important to note that the ERS does not include goats in their grain consumption calculations.

Since NASS does not collect yearly numbers on horses, the AMS does not estimate horse population and its contribution to feed demand at the state-level. However, Virginia's horse industry had a total sales impact of $\$ 1.2$ billion in 2010 [16]. Thus, horses are a relevant part of the state's agriculture and merit inclusion in the feed consumption estimates. In terms of potential data sources, NASS gathers information on the inventory of horses (and mules) in the Census of Agriculture, which gives data points exist for 1997, 2002, 2007, and 2012. However, these inventories are only the number of horses on farms, which likely underestimates Virginia's total horse population. ${ }^{35}$ On the other hand, NASS did conduct a full-scale equine survey in 1998 and 1999, and the NASS Virginia Field Office conducted their own surveys in 2001 and 2006. Data from these reports are used in the current study. For the years without data, the horse population in Virginia is approximated by using the 1998 value for 1992-97 period; the average of the 1999 and 2001 values for 2000; the average of the 2001 and 2006 values for 2002-05 period; and the 2006 value for 2007-14 period.

\section{Additional County-Level Methodology}

County-level data for cattle come from the "Cattle and Calves-Inventory and Sales" table of the Census, which provides the cattle inventories in Virginia as of December 31, 2012. Inventories of dairy cows and beef cattle on feed are available. "Other beef cattle" is normally calculated by subtracting dairy cattle, dairy heifers, and beef cattle on feed from the variable representing all of Virginia's cattle. However, since the Census does not collect information on dairy heifers, those cattle are part of the "other" category. ${ }^{36}$

Table 6 shows a summary of the cattle information available at the state-and county-levels, and the degree to which Census variables match the expected population (magnitude accuracy) and the amount of disclosed information (distribution accuracy). Since inventory is a variable collected in both the Census and on an annual basis, the estimated county-level grain consumption by cattle should be accurate; "magnitude accuracy" is not an issue. Moreover, the distribution should be relatively accurate because much of the data is disclosed.

Table 6. Comparison of state-and county-level Virginia cattle.

\begin{tabular}{|c|c|c|c|}
\hline & Dairy Cattle & Beef Cattle, on Feed & All Cattle ${ }^{\mathrm{a}}$ \\
\hline \multicolumn{4}{|l|}{ State-Level Variable: } \\
\hline Type & Inventory & Inventory & Inventory \\
\hline Time Frame/Date & Jan. 1, 2013 & Jan.1, 2013 & Jan. 1, 2013 \\
\hline Amount & 94,000 & 23,000 & $1,610,000$ \\
\hline \multicolumn{4}{|l|}{ County-Level Variable: } \\
\hline Type & Inventory & Inventory & Inventory \\
\hline Time Frame/Date & Dec. 31, 2012 & Dec. 31, 2012 & Dec. 31, 2012 \\
\hline Amount & 94,105 & 20,010 & $1,631,882$ \\
\hline Percentage Difference & $0.1 \%$ & $-13.0 \%$ & $-1.4 \%$ \\
\hline Amount Disclosed & 89,068 & 14,195 & $1,631,882$ \\
\hline Amount Non-Disclosed & 5,037 & 5,815 & 0 \\
\hline Percent Disclosed & $94.6 \%$ & $70.9 \%$ & $100.0 \%$ \\
\hline Percent Non-Disclosed & $5.4 \%$ & $29.1 \%$ & $0.0 \%$ \\
\hline
\end{tabular}

a. "Other cattle" is derived from these three and is, therefore, not included.

\footnotetext{
${ }^{35}$ For example, the 2007 Census estimated that Virginia had 97,112 horses and mules (on farms), while the 2006 report from the NASS Virginia Field Office estimated that the entire state of Virginia had 215,000 horses and mules.

${ }^{36}$ Since the GCAU factor is lower for “other beef cattle” than for “dairy heifers," grain consumption may be underestimated.
} 
Broilers, turkeys, layers, and pullets make up Virginia's poultry population. As stated previously, the ERS annual population estimations use production (in head) for broilers and turkeys; average monthly inventory for layers; and a lengthier derivation for pullets. Though NASS collects these variables on a yearly basis, it does not gather the same data in the Census. Instead, three variables for (all) livestock are gathered: 1) number in inventory (on December 31 in the Census year); 2) number produced under a production contract in the Census year; and 3) number moved or sold by the operation in the Census year. ${ }^{37}$

Given the relatively quick cycle in broiler and turkey production $[38],{ }^{38}$ the number moved or sold is likely to better proxy for expected broiler and turkey populations. Therefore, this measure is assumed to be a more accurate reflection at the county-level than inventory. Next, since the annual layer population is derived from inventory data, the inventory variable for layers in the Census is a satisfactory proxy to examine the population at the county-level. Finally, inventory was selected to conservatively represent the number of pullets at the county-level. ${ }^{39}$

Table 7 contains a summary of the poultry information in the annual calculations and Census, which reflects any bias due to the magnitude and distributional accuracy issues. In terms of the former, three of the selected Census variables (broilers, turkeys, and layers) strongly resemble their annual counterparts, which imply that they are good approximations of the expected populations (though turkeys appear to be overestimated). However, with a percentage difference of 86 percent, the number of pullets seems to be substantially underestimated. Even so, as previously mentioned, the number of available variables is limited in the Census and inventory still serves as a reasonable and adequate proxy of Virginia's pullet population.

In terms of distributional accuracy across counties, large shares of broilers and turkeys moved/sold are disclosed, but portions of the layer and pullet populations are non-disclosed, which impacts exactness of the distribution. However, these the layer and pullet poultry groups account for a small share of grain consumption relative to broilers and turkeys and, as a result, do not present a significant issue. In terms of location, the four selected variables accurately portray Virginia's poultry populations and, hence, their grain consumption at the county-level.

Applied in the annual calculations, the Economic Research Service uses the "pig crop" to estimate the number of feeding hogs and their overall grain consumption. However, NASS does not collect information on the "pig crop" in the Census. In its place, inventory is used to estimate Virginia's pig population at the county-level.

Table 7. Comparison of state-and county-level Virginia poultry.

\begin{tabular}{ccccc}
\hline & Broilers & Turkeys & Layers & Pullets \\
\hline State-Level Variable: & Production & Production & Calculation \\
(head) & 2012 & 2012 & Inventory & 2012 \\
Type & $242,450,000$ & $17,000,000$ & Monthly, 2012 & $8,862,281$ \\
Amount & & $2,883,750$ & Inventory \\
County-Level Variable: & Sold/Moved & Sold/Moved & Inventory & Dec. 31,2012 \\
Type & 2012 & 2012 & Dec. 31,2012 & $1,301,917$ \\
Time Frame/Date & $237,669,378$ & $18,223,608$ & $2,897,238$ & $-85.3 \%$ \\
Amount & $-2.0 \%$ & $7.2 \%$ & $0.5 \%$ & 961,103 \\
Percentage Difference & $231,854,347$ & $17,877,630$ & $1,630,571$ & 340,814 \\
Amount Disclosed & $5,815,031$ & 345,978 & $1,266,667$ & $73.8 \%$ \\
Amount Non-Disclosed & $97.6 \%$ & $98.1 \%$ & $56.3 \%$ & $26.2 \%$ \\
Percent Disclosed & $2.4 \%$ & $1.9 \%$ & $43.7 \%$ & \\
Percent Non-Disclosed & & & & \\
\hline
\end{tabular}

\footnotetext{
${ }^{37}$ More specifically, inventory generally refers to the number on-hand. A “production contract refers to "an agreement between a producer or grower and a contractor (integrator) setting terms, conditions, and fees to be paid by the contractor to the operation for the production of crops, livestock, or poultry" and is included as part of total inventory and total moved. Total moved/sold refers to the number sold or moved from the operation (which may result in one being sold twice).

${ }^{38}$ For example, a broiler can reach its market weight in five weeks [38].

${ }^{39}$ The number of pullets in inventory includes those in inventory on production contracts and is a more conservative variable than those "moved or sold" where several may be moved two or more times.
} 
Providing insight with respect to the issues of magnitude and distribution accuracy, Table 8 contains a summary of the hog information in the Census and annual calculations. First, though inventory overestimates the expected hog population by 26 percent, it is arguably the best variable available in the Census. ${ }^{40}$ Second, since 63 percent of the hog population is non-disclosed, the distributional accuracy of the estimates is impacted. Thus, in order to distribute the non-disclosed inventory and increase accuracy, an additional data source for hog inventory in Virginia is used. NASS and the NASS Virginia Field Office have hog inventory data at the agricultural district level from 1988 through 2009 [39]. Virginia has seven agricultural districts so, while not as precise as counties in the Census, the data provide more information than just at the state-level. The basic idea requires weighting the non-disclosed counties according to their agricultural district as some districts have larger amounts of hogs than others.

More specifically, the steps include 1) calculate the percentage of Virginia's hogs in each agricultural district level from the 2009 Virginia Field Office report, the latest one available (this consists of dividing each district's inventory by the total population of hogs in Virginia); 2) calculate the percentage of Virginia's hogs in each agricultural district from disclosed ("known") Census values (which will naturally be smaller due to non-disclosed counties); 3) obtain the difference between the "expected" district percentage and the Census district percentage (for each district) to determine how much more is needed to have the percentages be equivalent; 4) determine how much of the non-disclosed hog information needs to go into each district to match percentages described in Step 3; and 5) divide the required amount per district equally across non-disclosed counties in that district. Overall, this procedure translates into increased accuracy at the county-level since amounts are no longer spread equally across non-disclosed counties.

Akin to cattle, NASS collects inventory data for sheep in the Census, which matches the variable used in the annual calculations. Specifically, county-level sheep data come from the "Sheep and Lambs-Inventory, Wool Production, and Number Sold" table, which provides the inventory of sheep and lambs on December 31, 2012. Table 9 contains a summary of the sheep information and indicates how closely Census variables match the expected population (magnitude accuracy) and the amount of disclosed information (distribution accuracy). Since inventory is the variable available in both the state and Census reports, it is an adequate measure to estimate grain consumption by sheep at the county-level. In addition, the location or spread across the counties is also accurate with almost all data being disclosed.

As mentioned earlier in the appendix, NASS does not collect information for horses on an annual basis. County-level data are available from two sources: the Census of Agriculture and the Virginia NASS Field Office. Data on horses from the Census is limited in Virginia because a large portion of the state's equine population is found off farms; the Census underestimates the total horse population in the state. Instead, information collected in a 2006 survey from the NASS Virginia Field Office is used because it is the most accurate and recent data

\section{Table 8. Comparison of state-and county-level Virginia pigs.}

\begin{tabular}{cc}
\hline State-Level Variable: & Pigs \\
Type & Pig Crop \\
Time Frame/Date & 2012 \\
Amount & 190,400 \\
County-Level Variable: & Inventory \\
Type & Dec. 31,2012 \\
Time Frame/Date & 239,899 \\
Amount & $26.0 \%$ \\
Percentage Difference & 87,799 \\
Amount Disclosed & 152,100 \\
Amount Non-Disclosed & $36.6 \%$ \\
Percent Disclosed & $63.4 \%$ \\
\hline
\end{tabular}

\footnotetext{
${ }^{40}$ Those under a production contract are included in inventory and the number moved or sold (of 559,658) exceeds the expected population by 193.9 percent. This suggests that some are moved or sold more than once during the year.
} 
Table 9. Comparison of state-and county-level Virginia sheep.

\begin{tabular}{cc}
\hline State-Level Variable: & Sheep \\
Type & Inventory \\
Time Frame/Date & Jan. 1, 2013 \\
Amount & 87,000 \\
County-Level Variable: & Inventory \\
Type & Dec. 31, 2012 \\
Time Frame/Date & 84,983 \\
Amount & $-2.3 \%$ \\
Percentage Difference & 84,718 \\
Amount Disclosed & 265 \\
Amount Non-Disclosed & $99.7 \%$ \\
Percent Disclosed & $0.3 \%$ \\
Percent Non-Disclosed &
\end{tabular}

Table 10. Information on county-level Virginia horses.

\begin{tabular}{cc}
\hline County-Level Variable: & Horses \\
Type & Inventory \\
Time Frame/Date & Nov. 1, 2006 \\
Amount & 215,000 \\
Amount Disclosed & 199,200 \\
Amount Non-Disclosed & 15,800 \\
Percent Disclosed & $92.7 \%$ \\
Percent Non-Disclosed & $7.3 \%$ \\
\hline
\end{tabular}

available on the total population and distribution of Virginia's horses. ${ }^{41}$ The selected variable represents the number of horses, ponies, and mules in inventory in Virginia on November 1, 2006.

Table 10 provides summary data on Virginia's horses to examine the accuracy of its distribution on a map [40]. In this case, "magnitude accuracy" is not a problem because the annual estimates use the same data. Also, since much of the data is disclosed (almost 93 percent), the distribution is accurate. Further, since the Virginia NASS Field Office provides information on the non-disclosed quantities in each agricultural district, the accuracy of the distribution can be enhanced.

\footnotetext{
${ }^{41}$ For example, according to the 2007 Census of Agriculture, the number of horses and mules on Virginia's farms was 97,112. The Virginia NASS Office estimated that Virginia had a population of 215,000 horses in 2006-a 121 percent difference.
} 